\title{
Mental workload and affecting factors among firefighters in Tehran, Iran, in 2017
}

\author{
Laal F, PhD Student ${ }^{1}$, Jafari MJ, $\mathrm{PhD}^{2 *}$, Noorizadeh N, MSc${ }^{3}$, Fallah Madvari R, $\mathrm{MSc}^{4}$, \\ Rahimi E, $\mathrm{PhD}^{5}$, Ahmadi E, $\mathrm{BSc}^{6}$ \\ 1- PhD Student in Occupational Health, Student Research Committee, Dept. of Occupational Health, School of Public \\ Health, Shahid Beheshti University of Medical Sciences, Tehran, Iran. 2- Professor, Dept. of Occupational Health \\ Engineering, Faculty of Health, Shahid Beheshti University of Medical Sciences, Tehran, Iran. 3- MSc in Occupational \\ Health, Dept. of Occupational Health, School of Public Health, Shahid Beheshti University of Medical Sciences, Tehran, \\ Iran. 4- MSc in Occupational Health, Dept. of Occupational Health, Shahid Sadoughi University of Medical Sciences, Yazd, \\ Iran. 5- PhD in Epidemiology, Dept. of Public Health, Mamasani Higher Education Complex for Health, Shiraz University \\ of Medical Sciences, Shiraz, Iran. 6- BSc in Biology, Birjand University, Birjand, Iran.
}

\begin{abstract}
Received: July 2017, Accepted: November 2017

Background: Firefighting and rescue require high physical and psychological needs under unpredictable and dangerous conditions. Thus, this study aimed to investigate mental workload and affecting factors in firefighters.

Materials and Methods: This is a descriptive study which was conducted on 250 firefighters of Tehran, Iran. National Aeronautics and Space Administration Task Load Index (NASA-TLX) survey was used in order to evaluate the mental load among firefighters. This tool evaluates mental workload in 6 areas of mental need, physical need, time pressure, endeavor level, performance (efficiency) and disappointment level. Each area is investigated with a scale from zero to 100. Finally, data were analyzed using descriptive statistics, Pearson correlation test and linear regression.

Results: The mean and standard deviation (SD) of age in firefighters was $32.20 \pm 4.54$ years. The physical load dimension $(93.48 \pm 8.93)$ had highest value and disappointment and failure feeling $(25.85 \pm 23.38)$ had the lowest value in terms of mental workload. Association with educational level and the physical load was direct and significant $(\mathrm{P}=0.035)$. None of the demographic variables including age, working history, educational level, marital status, as well as being smoker had an impact on total mental workload $(\mathrm{P}>0.050)$.

Conclusions: Overall mental workload was high in firefighters which can influence working efficiency and increase errors in this occupational group. Hence, implementing effective programs for adjusting mental workload such as ergonomic and psychological interventions are recommended for reducing mental and psychological errors and stress.
\end{abstract}

Keywords: Workload, Firefighters, National Aeronautics and Space Administration

\section{Introduction}

One of the current industrial problems of the world is the early departure of workers from the workplace. Despite increasing life expectancy, improving living conditions, and better health status in the communities, average period of work time of employed people has reduced in the European countries in recent decades, as a result of mental and psychological accidents and stress (1). Firefighting and rescue require high physical and psychological needs for decision making and taking action under unpredictable and dangerous conditions. For performing working tasks without stress, firefighters should have good health and high physical and psychological capacity. Physical working capacity as an occupational need should remain at a high level during the career period; however, old firefighters face specific

* Corresponding author: Mohammad Javad Jafari, Dept. of Occupational Health Engineering, Faculty of Health, Shahid Beheshti University of Medical Sciences, Tehran, Iran.

E-mail: Jafari1952@yahoo.com 
challenges regarding the ability to work and physical readiness (2). Thus, in order to ensure achievement of safety, health, and comfort in the workplace and increase productivity and efficiency of the operator in a long-term period, the logical and rational goal is to set the work-related needs in such a way that are not beyond the one's ability $(3,4)$. Individual and environmental factors in the workplace, directly and indirectly, influence the productivity of human forces (5). One of the components affecting health, safety, and comfort of individuals is workload and job stress which are directly associated with one's performance (6). Therefore, workload and its impacts on the organizations have become one of the main issues of organizational behavior in the recent decade (7). An assessment of workload is important for estimating job cognitive needs and for predicting staff capacity to perform tasks. (8). There are various reasons for paying high attention to measurement and evaluation of mental workload and its importance widely in the future. The first reason is changing nature of work from physical to cognitive and perceptual nature. The second reason is the accidents which are common in working environments and impose a high burden on manufacturing systems and the society. Such accidents cannot be eradicated and causes for their wide prevalence are related to the human factor. The third reason is human errors related to mental workload which mostly occur due to insufficient information processing in human. According to Smiley and Brookhuis report, it is the main reason for the prevalence of occupational accidents (9). According to the study by Malekpoor et al., aiming at the investigation of the relationship between quality of life and mental workload in nurses of Urmia University of Medical Sciences, it was found that intellectual and mental need has the highest and physical need has the lowest value compared to other workload areas (10). In addition, in the study by Bent and Bridger, which was done among salesmen, it was shown that average mental workload was efficient at a high level of satisfaction with performance (11). Given limited studies regarding mental workload among firefighters and diagnosis of affecting factors, this study intended to evaluate the mental workload and its effective factors in firefighters of Tehran, Iran.

\section{Material and Methods}

This is a descriptive-analytical study of the cross-sectional type which was conducted on 250 firefighters in Tehran following necessary coordination. Out of about 4000 personnel of Tehran firefighting and given statistical confidence as $95 \%$, the sample size was estimated as 200. It was raised to 250 for increasing the accuracy, according to the below formula:

$\mathrm{N}=\left(\frac{\mathrm{Z}^{2} \times \mathrm{SD}^{2}}{\mathrm{D}^{2}}\right), \quad \mathrm{N}:$ Sample Size, $\mathrm{Z}:$ The percentage error of the acceptable coefficient of confidence, SD: Standard deviation, and D: Degree of confidence.

Sampling was done as clustering sampling about 120 available working stations. 20 stations were selected randomly in four geographical regions of Tehran (north, south, west, and east) and a respective questionnaire was given to the individuals in the selected stations. National Aeronautics and Space Administration Task Load Index (NASATLX) survey was used in order to evaluate mental load among firefighters. Prior to completing the anonymous questionnaire, participants' consents were taken for participating in the research and if each of firefighters exited study for any reason (absence, reluctance for participation), the next one in the list was replaced. Inclusion criteria included working history more than one year and lack of any congenital jobmisrelated diseases. In addition, people with two jobs were excluded.

NASA-TLX is a multidimensional tool for evaluating mental workload in the form of a questionnaire which was developed by Human Performance Group in NASA Ames Research Center (2). NASA-TLX as the most powerful 
tool evaluates mental workload in 6 areas of mental need, physical need, time pressure (temporal load), effort and endeavor level, performance (efficiency), and disappointment level. Extensive studies of Human Factors Engineering Group of NASA organization have demonstrated that this questionnaire is a powerful tool for evaluating and reporting mental workload in different jobs (12). Face validity of Persian version of this questionnaire was confirmed by Mohammadi et al. and its internal reliability was assessed as acceptable $(\alpha=0.847)$ (13). This questionnaire evaluates mental workload in above six axes. Meanwhile, each dimension included one question which was examined on every axis. Except for performance or efficiency axes, which are evaluated between good and bad levels, other axes are evaluated between high and low levels. Each of axes is investigated with a scale from zero to 100 . Therefore, we used this method to evaluate mental workload and affecting factors on firefighters. Finally, data were analyzed by SPSS software (version 21, IBM Corporation, Armonk, NY, USA) using descriptive statistics, Pearson correlation test and linear regression. In addition, the significance level was considered as 0.050 in this study.

\section{Results}

Table 1: Total mental workload and its dimensions in firefighters of Tehran, Iran, in 2017

\begin{tabular}{cccc}
\hline Dimensions of mental workload & Mean \pm SD & Minimum & Maximum \\
\hline Intellectual and mental load & $92.28 \pm 10.21$ & 40 & 100 \\
\hline Physical load & $93.48 \pm 8.93$ & 30 & 100 \\
\hline Temporal pressure & $92.64 \pm 10.87$ & 20 & 100 \\
\hline Amount of effort and endeavor & $89.40 \pm 13.17$ & 20 & 100 \\
\hline Performance & $26.81 \pm 21.59$ & 1 & 100 \\
\hline Disappointment and failure feeling & $25.85 \pm 23.38$ & 1 & 100 \\
\hline Total mental workload & $70.07 \pm 6.58$ & 55 & 95 \\
\hline
\end{tabular}

SD: Standard deviation

Table 2 indicates an association between different variables of total mental workload and its dimensions using linear regression. Considering the table 2, the association between educational level with physical load was direct and significant $(\mathrm{P}=0.035)$, and its relationship with the performance was inverse
The mean \pm relative SD of the age of firefighters was $32.30 \pm 4.54$, ranging from 22 to 50 years. In terms of educational level distribution in the studied population, participants with high school diploma made the largest part of the research population as 114 (45.6\%). Then, participants with Bachelor of Science (BSc) education $(n=79,31.6 \%)$, associate degree $(n=53,21.2 \%)$ and Master of Science (MSc) and above ( $\mathrm{n}=4,1.6 \%)$ were in the next ranks. Mean and SD of working history of participants was $7.36 \pm 4.57$ years. The participants had minimum 1 year and maximum 29 years of working history. Also, 190 (76\%) firefighters were married and 197 (78.8\%) had no operation before the interview. Additionally, all participants were men and had rotational shift work. Most of firefighters $(\mathrm{n}=215,86 \%)$ had normal blood pressure. Pearson correlation results suggested a significant association between dimensions of mental workload and total mental workload ( $\mathrm{P}$ $<0.050$ ). Considering table 1 , physical load dimension $(93.48 \pm 8.93)$ had highest value and disappointment and failure feeling (25.85 $\pm 23.38)$ had the lowest value in terms of mental workload. The total mental workload was $70.07 \pm 6.58$. 
variable is obtained. According to the results, none of the demographic variables including age, working history, educational level, marital level, as well as being smoker had the impact on total mental workload $(\mathrm{P}>0.050)$. Total workload was reduced by increasing age and educational level, but the total mental workload was increased by elevated working history. However, this relationship was not significant.

Table 2: Relationship between demographic variables and being smoker and total mental workload and its dimensions using linear regression

\begin{tabular}{|c|c|c|c|c|}
\hline Dimensions of $\mathrm{me}$ & tal workload & Coefficient (B) & Standard error & $\mathbf{P}^{*}$ \\
\hline \multirow{5}{*}{$\begin{array}{l}\text { Intellectual and } \\
\text { mental load }\end{array}$} & Age & 0.088 & 0.340 & 0.796 \\
\hline & Education level & 0.916 & 0.765 & 0.232 \\
\hline & Work history & -0.222 & 0.335 & 0.507 \\
\hline & Being smoking & 0.344 & 0.366 & 0.348 \\
\hline & Marital status & 0.815 & 1.609 & 0.613 \\
\hline \multirow{5}{*}{ Physical load } & Age & -0.214 & 0.295 & 0.468 \\
\hline & Education level & 1.403 & 0.663 & 0.035 \\
\hline & Work history & 0.052 & 0.290 & 0.858 \\
\hline & Being smoking & 0.505 & 0.317 & 0.112 \\
\hline & Marital status & -0.055 & 1.394 & 0.696 \\
\hline \multirow{5}{*}{ Temporal pressure } & Age & 0.264 & 0.359 & 0.464 \\
\hline & Education level & -0.094 & 0.807 & 0.907 \\
\hline & Work history & 0.062 & 0.353 & 0.862 \\
\hline & Being smoking & -0.704 & 0.386 & 0.069 \\
\hline & Marital status & -0.152 & 1.697 & 0.929 \\
\hline \multirow{5}{*}{$\begin{array}{l}\text { Amount of effort } \\
\text { and endeavor }\end{array}$} & Age & -0.645 & 0.431 & 0.136 \\
\hline & Education level & 1.589 & 0.969 & 0.102 \\
\hline & Work history & 0.932 & 0.424 & 0.029 \\
\hline & Being smoking & -0.283 & 0.463 & 0.542 \\
\hline & Marital status & -3.405 & 2.038 & 0.096 \\
\hline \multirow{5}{*}{ Performance } & Age & 0.296 & 0.708 & 0.677 \\
\hline & Education level & -4.301 & 1.591 & 0.007 \\
\hline & Work history & 0.008 & 0.696 & 0.991 \\
\hline & Being smoking & -1.352 & 0.761 & 0.077 \\
\hline & Marital status & -2.306 & 3.346 & 0.491 \\
\hline \multirow{5}{*}{$\begin{array}{l}\text { Disappointment and } \\
\text { failure feeling }\end{array}$} & Age & -1.324 & 0.774 & 0.088 \\
\hline & Education level & -1.379 & 1.738 & 0.428 \\
\hline & Work history & 1.445 & 0.760 & 0.059 \\
\hline & Being smoking & 0.473 & 0.831 & 0.570 \\
\hline & Marital status & -4.177 & 3.657 & 0.254 \\
\hline \multirow{5}{*}{$\begin{array}{l}\text { Total mental } \\
\text { workload }\end{array}$} & Age & -0.256 & 0.218 & 0.241 \\
\hline & Education level & -0.311 & 0.490 & 0.526 \\
\hline & Work history & 0.379 & 0.214 & 0.078 \\
\hline & Being smoking & -0.170 & 0.234 & 0.470 \\
\hline & Marital status & -1.547 & 1.030 & 0.134 \\
\hline
\end{tabular}

* Linear regression model

\section{Discussion}

Mental workload is one of the factors affecting individuals' behavior and performance and thus the productivity. Activities such as firefighting, which needs focusing, the speed of action, and appropriate control action at the shortest time, impose high mental and physical burden on the employers. Total mental workload was 7.70 in this research. Also, workload in different dimensions was high except for the performance, disappointment and boredom. It was almost consistent with the study by Zakerian et al. (14). Given results of 
this study, individual characteristics such as age, marital status, working history, educational level, as well as being smoker were not effective on total mental workload, which was consistent with findings reported by Zamanian et al. (15) and Denison (16). Zamanian et al. conducted a study aiming at investigating mental workload and job satisfaction and found that demographic characteristics had no impact on workload and job satisfaction (15). Haghi et al., using linear regression, showed that age, working history, educational level, marital status, work shift, and a number of working missions had no impact on average mental workload (17). In the study by Zakerian, it was found that boredom and disappointment and performance were higher and lower in shift workers compared to non-shift workers, respectively (14), while all firefighters had rotational shift works. Hoonakker in a study on nurses showed that physical load was lower in older nurses than younger ones (18), while Malekpoor found that age and working history had no impact on workload (10). In this study, there was no significant association between educational level and age with mental load score, but in the study by Young et al., mental load score was significantly related to age differences and older workers were more vulnerable to mental load compared to younger workers (19). Roja et al. conducted a study aiming at evaluating mental and physical load of firefighters and found that physical load had the highest value and total mental workload based on NASA questionnaire was 58 and 65 in two groups of firefighters and commanding officers respectively (20). Overall considering contradiction in different studies two conclusions can be achieved. First, demographic factors had no impact on workload and other factors should be found in firefighters. Second, the sample size of the current work was small and accordingly, the modeled variables were not significant. Thus, some of these factors may be effective and it is suggested that larger sample size is considered in future works.

\section{Conclusion}

Generally, results of this study showed that mental workload is high in firefighters which may influence their work efficiency and increasing errors in this occupational group. Also, like many national and international studies, results of this study showed individual characteristics such as age, marital status, working history, educational level, as well as being smoker were not effective on total mental workload. High focus, accuracy, and endeavor in this risky job are factors for the high mental workload in firefighters. Fatigue resulting from physical pressures to muscles and environmental factors and psychological stress are major factors of the high mental workload in firefighters. Although these individuals pass various screening for recruitment and they should be in the best condition in terms of physical and psychological readiness, the physical, psychological and mental pressures on them after recruitment should be considered. Unfortunately, limited studies have been conducted in this regards in Iran. Therefore implementing effective programs for adjusting mental workloads and ergonomic and psychological interventions are recommended for reducing errors and psychological stress.

\section{Acknowledgements}

This study is related to the project number 2804/1395, from Student Research Committee, Shahid Beheshti University of Medical Sciences, Tehran. We also appreciate the Student Research Committee and Research and Technology Chancellor of Shahid Beheshti University of Medical Sciences for their financial support of this study.

Conflict of interest: None declared.

\section{References}


1. Ilmarinen JE. Aging workers. Occup Environ Med 2001; 58(8):546-52.

2. Kiss $\mathrm{P}$, Walgraeve $\mathrm{M}$, Vanhoorne M. Assessment of work ability in aging fire fighters by means of the Work Ability Index: preliminary results. Arch Public Health 2002; 60:233-44.

3. Cao A, Chintamani KK, Pandya AK, Ellis RD. NASA TLX: software for assessing subjective mental workload. Behav Res Methods 2009; 41(1):113-7.

4. Safari Sh, Mohammadi Bolbanabad H, Kazemi M. Evaluation of mental load of work in nurses of intensive care unit using burden of mind index (NASA). Journal of Health System Research 2013; 9(6):613-9.

5. Alavinia SM, Hosseini SH. Work ability index, an important tool in occupational health and medicine to define workers at risk for early exit from work force. Journal of North Khorasan University of Medical Sciences 2011; 3(2):49-53.

6. Burton WN, Conti DJ, Chen CY, Schultz AB, Edington DW. The role of health risk factors and disease on worker productivity. J Occup Environ Med 1999; 41(10):863-77.

7. Malekpour F, Mohammadian Y, Malekpour AR, Mohammadpour Y, Sheikh Ahmadi A, Shakarami A. Assessment of mental workload in nursing by using NASA-TLX. Journal of Urmia Nursing and Midwifery Faculty 2014; 11(11):892-99.

8. Weinger, MB, Reddy SB, Slagle JM. Multiple measures of anesthesia workload during teaching and nonteaching cases. Anesth Analg 2004; 98(5):1419-25.

9. Rothengatter $\mathrm{T}$, de Bruin RA, Rijksuniversiteit te Groningen. Verkeerskundig Studiecentrum. Road users and traffic safety. $1^{\text {st }}$ ed. Assen/ Maastricht, Netherlands: Van Gorcum \& Comp BV; 1987.

10. Malekpour F, Mohammadian Y, Mohamadpour Y, Fazli B, Hassanloei B. Assessmen of relationship between quality of life and mental workload among nurses of Urmia Medical Science University hospitals. Journal of Urmia Nursing and Midwifery Faculty 2014; 12(6):499-505.
11. Bridger RS, Bennett AI. Age and BMI interact to determine work ability in seafarers. Occup Med (Lond) 2011; 61(3):157-62.

12. Hart SG. Nasa-Task Load Index (NASA-TLX); 20 years later. Proc Hum Factors Ergon Soc Annu Meet 2006; 50(9):904-8.

13. Mohammadi M, Mazloumi A, Nasl Saraji J, Zeraati H. Designing questionnaire of assessing mental workload and determine its validity and reliability among ICUs nurses in one of the TUMS's hospitals. Journal of School of Public Health and Institute of Public Health Research 2013; 11(2):87-96.

14. Zakerian SA, Abbasinia M, Mohammadian F, Fathi A, Rahmani A, Ahmadnezhad I, et al. The relationship between workload and quality of life among hospital staffs. Journal of Ergonomics 2013; 1(1):43-56.

15. Zamanian Z, Roshan Sarvestani M, Sedaghati M, Ghatmiri M, Kouhnavard B. Assessment of the relation between subjective workload and job satisfaction in university faculty and staff. Journal of Ergonomics 2016; 3(4):1-10.

16. Loveridege C. Nursing management in the new paradigm. $1^{\text {st }}$ ed. Silver Spring, Maryland, United States: Aspen; 1996. P.204.

17. Haghi A, Rajabi H, Habibi A, Zeinodini M. Evaluation of mental workload on complex missions emergency personnel NASA-TLX. Occupational Medicine Quarterly Journal 2016; 7(3):37-45.

18. Hoonakker P, Carayon P, Gurses A, Brown R, McGuire K, Khunlertkit A, et al. Measuring workload of ICU nurses with a questionnaire survey: the NASA Task Load Index (TLX). IIE Trans Healthc Syst Eng 2011; 1(2):131-43.

19. Young G, Zavelina L, Hooper V. Assessment of workload using NASA Task Load Index in perianesthesia nursing. J Perianesth Nurs 2008; 23(2):102-10.

20. Roja Ž, Kalı̧is V, Kalı̧is H, Pencis I. Assessment of firefighters-rescuers' work severity in relation with interaction between physical and mental load. Proc Latv Acad Sci B Nat Exact Appl Sci 2009; 63(6):264-70. 